Avrupa Bilim ve Teknoloji Dergisi

Özel Sayı, S. 1-8, Ekim 2019

(C) Telif hakkı EJOSAT'a aittir

Arastırma Makalesi
European Journal of Science and Technology

Special Issue, pp. 1-8, October 2019

Copyright (C) 2019 EJOSAT

Research Article

\title{
Bakıma İhtiyaç Duyan Yaşlılar İçin Yardımcı Sosyal Robot Araştırması ve Analizi
}

\author{
Kerime Arzu Baloğlu ${ }^{*}$, Uğur T. Kaplancalı², Selcen Kılıç \\ ${ }^{1}$ Marmara Üniversitesi, Mühendislik Fakültesi, Bilgisayar Mühendisliği, İstanbul, Türkiye (ORCID: 0000-0003-1885-1965) \\ ${ }^{2}$ Yeditepe Üniversitesi, Ticari Bilimler Fakültesi, Yönetim Bilişim Bölümü, İstanbul, Türkiye (ORCID: 0000-0002-2911-7195) \\ 3 İstanbul Arel Üniversitesi, Sosyal Bilimler Enstitüsü, İşletme - Yönetim ve Organizasyon, İstanbul, Türkiye (ORCID: 0000-0002-4615-2726)
}

(Bu yayın HORA kongresinde sözlü olarak sunulmuştur.)

(İlk Geliş Tarihi 11 Temmuz 2019 ve Kabul Tarihi 27 Eylül 2019)

(DOI: $10.31590 /$ ejosat. 626045)

ATIF: Baloğlu, A., Kaplancalı, U. T., \& Kılıç, S. (2019). Bakıma İhtiyaç Duyan Yaşlılar İçin Yardımcı Sosyal Robot Araştırması ve Analizi. European Journal of Science and Technology, (Özel Sayı), 1-8.

\section{$\ddot{O} \mathbf{z}$}

Türkiye'de yaşlı nüfus son beş yılda \%17 artış göstermiştir. TÜİK nüfus projeksiyonlarına göre, Türkiye'de yaşlı nüfus oranının 2023 yılında \%10.2, 2040 yılında \%16.3, ve 2080 yılında \%25.6 olacağını öngörmektedir. Çoğu yaşlı mümkün oldukça kendi evlerinde yaşamlarını sürdürmeyi tercih etmektedirler. Benzer şekilde, ülkemizde yapılan araştırmalar yaşlıların kendi sağlık tercihleri doğrultusunda ve çocuklarına yakın çevrede oturup iletişimlerini devam ettirmek istediklerini göstermektedir. Hızla gelişen sağlık endüstrisine son yıllarda en büyük katkı bilişim ve ağ teknolojilerinden gelmekte, buna bağlı olarak toplumda sağlıklı yaşlanma ve yaşam beklentileri de yükselmektedir. E-sağlık teknolojileri ve robotlar bu noktada önemli bir potansiyele sahiptir. Biz bu çalışmamızda bakıma ihtiyaç duyan yaşlıların evde bulunan bir robot yardımcıdan neler beklediklerini araştırdık. Türkiye genelinde yapılan anketle, 60 yaş üzerindeki bireylere evde bulunan bir robot yardımcıdan beklentileri ile ilgili sorular yöneltildi. Araştırma sonuçları ülkemizde robot üretim ve geliştirme projelerinde yardımcı robotun öncelik verilecek yeteneklerinin belirlenmesinde kullanılabilir.

Anahtar Kelimeler: Robot yardımcı, Yaşıı bakımı, Yaşlıların beklentileri, e-sağlık.

\section{Social Robot Research and Analysis for Elderly People in Need of Care}

\begin{abstract}
Turkey showed a 17\% increase in the elderly population in the last five years. According to population projections of TÜIK, in 2023 the ratio of the elderly population in Turkey will be $10.2 \%, 16.3 \%$ in 2040 , and it is predicted that in 2080 will go up to $25.6 \%$. Most elderly people prefer to live in their own homes as long as possible. Similarly, researches conducted in our country show that the elderly want to stay in close proximity to their children, according to their health preferences, and to continue their communication. In recent years, the biggest contribution to the rapidly developing health industry comes from information and network technologies, and thus, healthy aging and life expectations in society are also rising. E-health technologies and robots have significant potential at this point. In this study, we investigated what the elderly people in need of care expect from a robot helper at home. Questions about the expectations of a robot helper is directed to a population from seven regions of Turkey, who is over 60 years old. Research results can be used to determine the ability of the robot to be given priority in robot production and development projects in our country.
\end{abstract}

Keywords: Socially assistive robots, Elderly care, Expectations of the elderly, e-health.

\footnotetext{
* Sorumlu Yazar: Marmara Üniversitesi, Mühendislik Fakültesi, Bilgisayar Mühendisliği, İstanbul, Türkiye, ORCID: 0000-0003-1885-1965, karzubaloglu@gmail.com
} 


\section{Giriş}

Dünya genelinde 65 ve daha büyük yaştaki bireyler “yaşlı nüfus” olarak tanımlanmaktadır. 2030 yılında Amerika'da yaşlıların 70 milyonu geçmesi ve nüfusun \%19'unu oluşturması beklenmektedir. (Administration for Community Living, 2018) Japonya'da 2025 yılında nüfusun üçte birinin 65 yaşının üstünde olacağı tahmin edilmektedir ve yaşlı bakım personeli açığı vardır. (Babbage, 2013) Buna rağmen gelişmekte olan bölgelerin yaşlı nüfusu, gelişmiş bölgelere göre çok daha hızlı büyümekte. 1980'de gelişmekte olan ülkeler 60 yaş ve üstü kişilerin yüzde 56'sına ev sahipliği yapıyordu. 2017 rakamları ise dünyadaki yaşlıların üçte ikisinden fazlasının gelişmekte olan bölgelerde yaşadığını göstermekte. 2017 ve 2050 arasında, gelişmekte olan bölgelerde 60 yaş ve üstü kişilerin sayısının iki kattan fazla artarak, 652 milyondan 1.7 milyara çıkması beklenirken, gelişmiş bölgelerde yüzde 38 oranında bir artış olacağı tahmin edilmektedir (UN 2017).

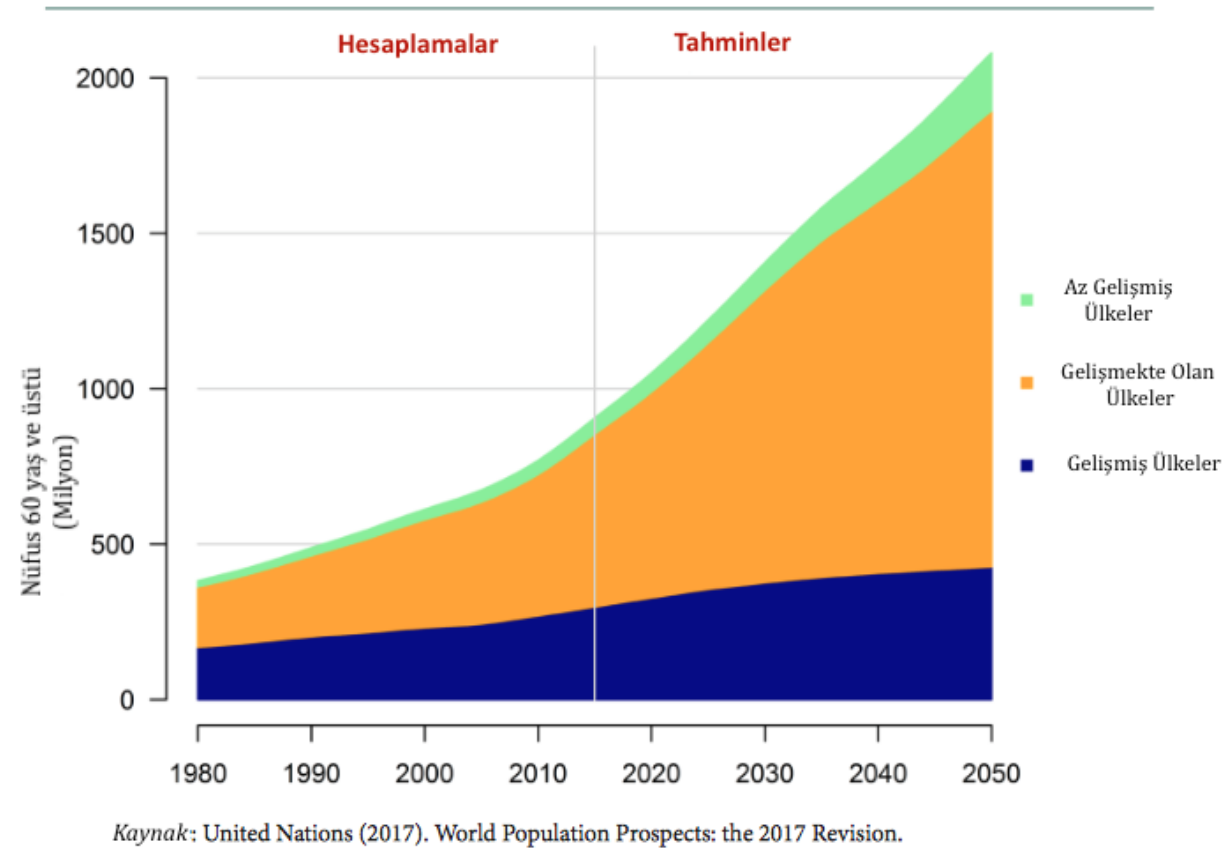

Şekil 1. Gelişmişlik grubuna göre 60 yaş ve üzeri kişi sayısı

Dünya Sağlık Örgütü (WHO, 2014) ve Türkiye İstatistik Kurumu'nun (TÜİK, 2018) verileri, Türkiye'de 60 yaş üstü nüfusun arttığını göstermektedir. Ülke genelinde bakım ve sağlık hizmetlerinde kaydedilen gelişmelerin sonucu olarak, yaşlı nüfusun genel nüfusa oranı yıllar içersinde yükselmiştir. TÜİK'in açıkladığı nüfus projeksiyonları, Türkiye'de yaşlı nüfus oranının 2017 y1lında $\% 8,5$ iken 2030 yılında oranın \%12,9'a yükseleceği ve 2080 yılında gelindiğinde ise ülke nüfusunun dörte birinin $(\% 25,6)$ yaşlı olacağını öngörmektedir.

Tablo 1: TÜİK Yıllara Göre Nüfus Projeksiyonları

\begin{tabular}{|c|c|c|c|c|c|}
\hline & 2017 & 2023 & 2030 & 2060 & 2080 \\
\hline $\begin{array}{c}\text { Yaşlı Nüfus } \\
\text { Oranı }\end{array}$ & $\% 8,5$ & $\% 10,2$ & $\% 12,9$ & $\% 22,6$ & $\% 25,6$ \\
\hline
\end{tabular}

Yaşlı kişilerin hane halkı yaşam düzenlemeleri ülkeler ve bölgeler arasında belirgin bir şekilde farklı olabilir ve bu durum aile büyüklüğüün yanı sıra nesiller arası ikameti çevreleyen sosyal ve kültürel normlardaki farklılıkların bir yansıması olarak açıklanabilir. 2010 yılında 60 yaş ve üzerindeki küresel nüfusun yüzde 71'ini temsil eden 67 ülkeye ait veriler (UN 2017), yaşlı insanların "bağımsız olarak yaşama” tercihlerinde bir artışa işaret ederken (2010'da yaklaşık yüzde 37, 1990'da yüzde 24'e kıyasla), daha az yaygın olan yaklaşımın “çocuklarla birlikte oturmak” olduğunu göstermektedir (2010'da yüzde 53, 1990'da yüzde 65'e kıyasla).

\footnotetext{
${ }^{1}$ Yaygın uygulama üzerinden "gelişmiş bölgeler”, Avrupa ve Kuzey Amerika'nın yanı sıra Avustralya, Yeni Zelanda ve Japonya'yı ve "gelişmekte olan bölgeler" dünyanın diğer tüm bölgelerini içerir.
} 
Sağlık endüstrisi, ekonomik, eğitimsel, bilimsel ve sosyal gelişmelerin etkisi ile ilerleme göstermekte, sağlıklı yaşlanma ve yaşam beklentileri de yükselmektedir. Hızla gelişen sağlık endüstrisine son yıllarda en büyük katkı bilişim ve ağ teknolojilerinden gelmekte. Teknolojinin benzer bir etkisini yaşlı bakım hizmetleri sektöründe de gözlemlemek mümkün. Son on yılda akıllı telefonları takip eden tablet ve akıllı saat teknolojileri özellikle sağlıklı yaşam konusunda sundukları uygulamalar ile öne çıkmakta. Bu mobil teknolojiler yanında, nesnelerin interneti kavramlarınca desteklenen akıllı sensörler ile inşa edilecek akıllı evler sayesinde güvenlik dahil birçok konuda tek başına yaşayan yaşlı insanların yaşam kalitesini yükseltecek modeller geliştirilmekte (Gyalog, 2017).

$\mathrm{Bu}$ çalışma, dünya genelinde önem kazanan yerinde yaşlanma olgusu ile (yaşlı bireyin ait olduğu yerden kopmadan kendi ev ortamında yaşantısına devam edebilmesi için gerekli imkanların sağlanması), bir yapay zeka teknolojisi olarak günlük hayatta kullanımının gittikçe artması beklenen robot olgusu arasındaki olası ilişki üzerinedir. Yapılan anket çalışması ile bakıma ihtiyaç duyan yaşlıların evde bulunan bir robot yardımcıdan neler beklediklerini araştırdık.

\section{Yaşlanma ve Robot Teknolojisi Literatür Taraması}

Günümüzde dünya ülkelerinde yaşlılara yönelik yürütülen hizmetler arasında en yaygını, hastanelerde ve hastanelerin geriatri ünitelerinde sunulan tıbbi hizmetlerdir. Diğer hizmetler arasında yaşlı bakım evleri, korunmalı meskenler, huzurevi, gündüz bakım merkezleri, yaşlı apartmanları ve yaşlı köylerini sayabiliriz (Akdemir, 2000). Turkiye'de ise aile bireyleri yaşlısına yönelik bakım aktivitelerinin büyük çoğunluğunu üstlenmektedir (Dogan, 2017). Benzer şekilde, ülkemizde yapılan araştırmalar yaşlıların "hem çocuklarına yakın çevrede oturup iletişimlerini devam ettirmek hem de kendi evlerinde yalnız yaşayıp, bağımsız bir hayat sürmeyi" istediklerine işaret etmekte (Çakmak, 2013, sayfa 40).

\subsection{Yerinde Yaşlanma}

Dünya Sağlık Örgütü’nün raporuna göre (WHO, 2014) büyük yetişkinlerin çoğu mümkün olduğu sürece evlerinde bağımsızlıklarını sürdürerek, kendi sağlık tercihleri doğrultusunda yaşlanmayı tercih etmektedirler. Yerinde yaşlanma (Aging in Place), bireyin alışık olduğu çevrede yaşlanabilmesine imkan veren mekanda gerekli toplum kaynaklarından ve bakım olanaklarından faydalanabilmesi esasına dayalıdır.

Doğan yerinde yaşlanmayı "yaşlıların evleriyle olan derin bağlarının farkında olan bir politikayı tanımlamak üzere kullanılan geniş kapsamlı bir terimdir" şeklinde tanımlıyor. (Dogan, 2017) Yerinde yaşlanmadan bahsedildiğinde mekan olarak yaşlının evinin yanı sıra, evin yer aldığı fiziksel çevre ve yaşlının etkileşimde bulunduğu sosyo-kültürel çevresi de anlaşılmalıdır. Yaşanan mekan; yaşlının kimliğinin bir parçasıdır ve gençliklerini geçirdikleri, alışageldikleri çevrede yaşamak kendilerini güvende hissetmelerini sağlar (Şentürk ve Kurtkapan, 2017).

Burdur ve Eğirdir Huzurevlerinde yerinde yaşlanma konusunda yapılan araştırma (Öğüt ve ark., 2017) yaşlıların kendi yaşam çevrelerinde, evlerinde aileleri ile birlikte yaşamayı özlediklerine işaret etmektedir. Yaşlılıkta genel eğilim bakım ve desteğin aile bireylerinden özellikle çocuklarından alınması yönündedir. Uzun dönemde aileler maddi manevi zorlanırken, yaşlılar için bağımlılık ve istismar riski artmaktadır. Yaşlıların hayattan kopmadan yalnız ve bağımsız yaşamasını destekleyecek modellerin uygulanması olumsuzlukları azaltacaktır (Aközer ve ark., 2011).

\subsection{Robotik Teknolojilerinin Yerinde Yaşlanmaya Katkısı}

Robotik teknolojilerindeki yenilikler yaşlı yetişkinlerin bazı bakım işlevlerini üstlenerek, bağımsız yaşayabilmelerine katkı sağlayabilir. Bakım robotlarının evrensel bir tanımı yoktur. Bakım robotları denildiğinde genel olarak sağlı personeline ya da bakım personeline bakım uygulamalarında entegre edilmiş teknolojik cihazlar algılanmaktadır. Yaşlı bakım robotları için farklı kategoriler tanımlanmıştır; örneğin yardımcı sosyal robotlar ve rehabilitasyon robotları (Broekens ve ark., 2009) ya da fiziksel yardım, refakât/arkadaşlık, ve sağlık durumu/güvenlik takibi yapan sağlık hizmeti robotları (Broadbent ve ark., 2009) ana kategorilerde yer almaktadir.

Bir bakım robotu; daVinci cerrahi robotunda olduğu gibi bir cerraha asistanlık yapabilir, TUG isimli robotun yaptığı gibi hastane içinde çarşaf, ilaç ya da materyalleri taşıyıp teslim edebilir (aethonrobotics, 2015), Georgia Tech Üniversitesi tarafından geliştirilen robot Cody gibi hastalara nazik bir yatak banyosu yaptırabilir ve giydirebilir (Park, 2016), inme hastalarının rehabilitasyonunda yardımcı olabilir (Lo ve ark., 2010), Robear gibi güçlü robotlar hastaları ayağa kaldırabilir ya da yataktan tekerlekli sandalyeye taşıyabilirken (Channel 7, 2015), Dinsow gibi küçük robotlar ilaçlarını almasını hatırlatabilir, kişisel asistanlık yapabilir, gözlemleyebilir, egzersiz yaptırıp, aramalarını yönetebilir (dinsowrobotic, 2016).

Robotların ağırlıkları, kaldırdıkları kişinin 10 katını bulduğundan, güçlü robotlar genellikle bakımevleri ve hastanelerde tercih edilmektedirler. Japonya'da Tsukuba Üniversitesi'nden Prof. Yoshiyuki Sankai'nin sahibi olduğu Cyberdyne şirketi tarafindan geliştirilen "Hibrit Yardımcı Uzuv" (HAL) adlı kıyafet, batarya ile çalışmakta ve sensörler sayesinde ayağa kalkıp yürümeyi düşünen kişinin hareketlerini mekanik olarak desteklemektedir. HAL'ın üst bedene giyilen bir diğer versiyonu da bakıcılara yaşlıları kaldırırken destek olmaktadır (Sankai, 2007; Ford, 2018). 


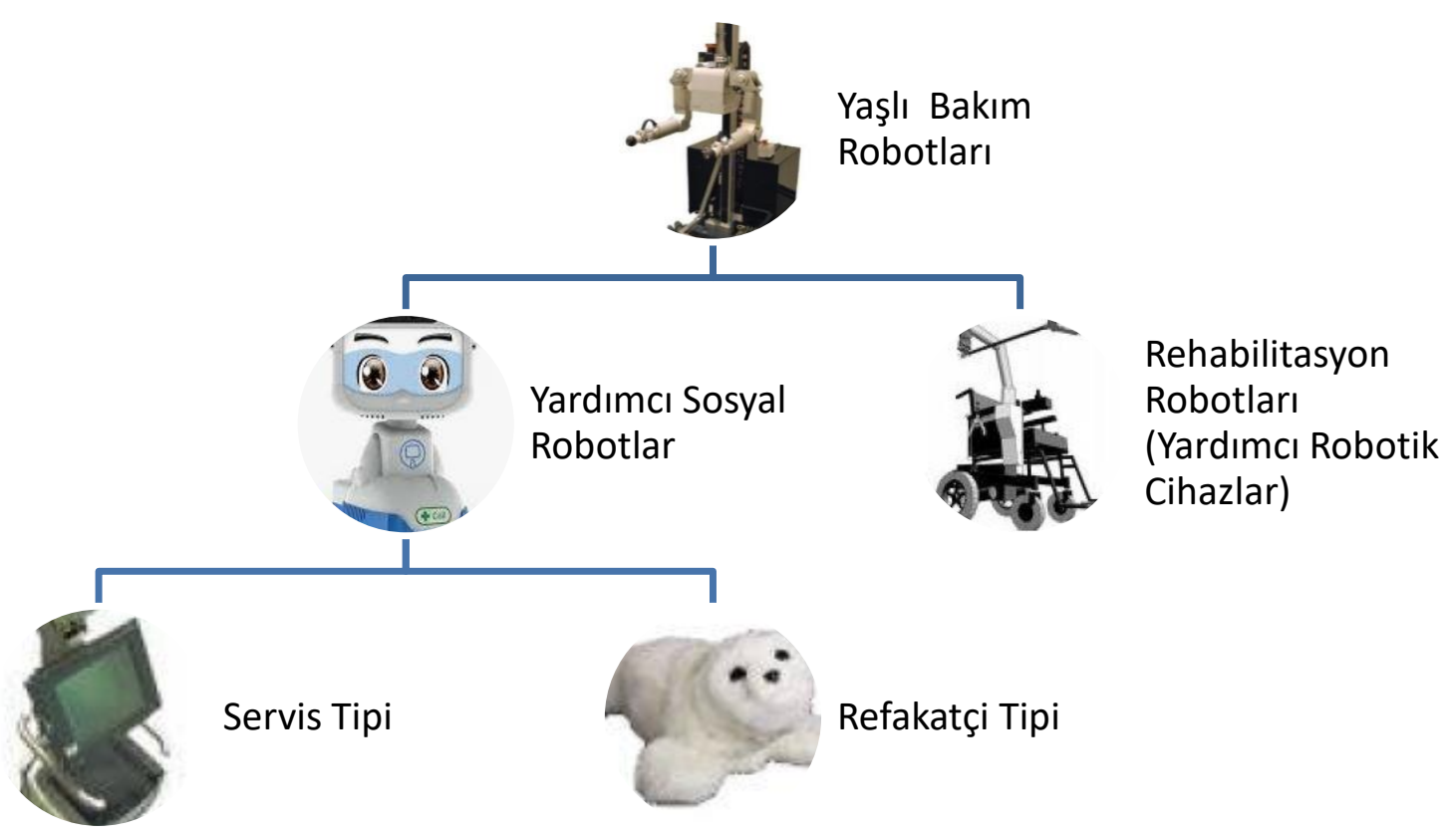

Şekil 2. Yardımcı Yaşlı Bakım Robotlarının Kategorizasyonu (Broekens ve ark., 2009)

Paro, Japonya'da özellikle demans hastalıkları olan yaşlılar için geliştirilmiş ilk bakım robotlarından biridir. Hareket edebilen ve dokunuşa cevap veren bir bebek fok formunda olan paro öğrenme yeteklerine sahiptir. (Financial Times, 2016) Teksas Üniversitesi'nde Dr. Sandra Petersen'in ekibinin demans hastaları üstünde yürütttüğü klinik deneylerde Paro'nun depresyon, endişe ve stres belirtilerini azalttığı ve ilaç kullanımının üçte bir oranında düştüğ̈̈ gözlenmiştir. (Mulligan, Gabriella; BBC, 2017) (Financial Times, 2016).

Singapur'daki Nanyang Teknoloji Üniversitesi'ndeki bilim adamları, "kendi kişiliği, ruh hali ve duyguları" ile tamamlanan, sosyal açıdan akıllı, insan görünümlü bir robot olan Nadine'i geliştirdiler. İnsansı bir robot olan Nadine, tanıştı̆ı insanları ve konuşulanları hatırlayabilme yeteneklerine sahip ve yakın gelecekte yaşlı ve çocuk bakımı evrelerinde hizmet verebilmesi yönünde çalışmalar yapılmakta (Tan, 2015).

Robotun ya da fonksiyonel olmayan bir robot veya evcil bir oyuncak gibi olan plasebo versiyonunun olumlu etkilerini gösteren çok sayıda çalışma göz önüne alındığında, yapay zeka destekli robotik teknolojilerinin yaşlı bakımında kesinlikle önemli olduğunu düşünüyoruz. Araştırmalar, beklenti ve algılara dayanarak bir kullanıcının robotla etkileşimin değerli olup olmadığına karar verdiğini göstermiştir (Komatsu, et.al.,2011). Dahası ve önemlisi, yaşlılar bu tür bir teknolojiye açık gibi görünmektedir ve geniş çaplı bir araştırma taraması sosyal yardımcı robotların yaşlı bakımı üzerindeki olumlu etkilerinin genele yayıldığını tespit etmiştir (Kachoui ve ark., 2014). Bu çalışma ile, Türkiye'de 60 yaş üzerindeki yetişkinlerin bir yardımcı bakım robotundan beklentilerinin belirlenmesini amaçladık.

\section{Yöntem}

Araştırma verileri olarak öncelikle anket örnek grubu tanımlanmıştır. Genellikle büyük ve hareketli illerde yaşayan ve kalabalık ailelere sahip olmayan yaşlanan nüfusun ihtiyacı belirlenmeye çalışılmıştır. Ayrıca, örneklemede yaş aralığı olarak henüz bilişsel sağlığı yerinde olan 60 yaşüzeri alınmıştır.

Marmara Bölgesi başta olmak üzere, Anadolu'nun büyük şehirlerini de içine alarak yapılan araştırmayı Türkiye'nin 7 bölgesinde yaşayan yaklaşık olarak 140 katılımcı cevaplamıştır. Anketin içeriği şu şekilde tasarlanmıştı; birinci bölüm demografik verilerini almak üzere diğer ve geniş bölüm ise yardımcı ev robotundan beklentilerini öğrenmek amacıyla kurgulanmış soru ve seçenekli cevaplardan ibarettir.

Anketin demografik betimleme soruları şöyledir: 1.Cinsiyetiniz nedir? Kadın=1, Erkek=2; 2. Kaç yaşındasınız? 61-70 yaş aralığı=1, 71-80 yaş aralığı $=2,81-90$ yaş aralığı $=3,91$ 'den büyük $=4$; 3 . Eğitim durumunuz nedir ? : Okuma-yazma bilmiyor=1, İlkokul=2, Ortaokul $=3$, Lise $=4$, Üniversite $=5$, Yüksek Lisans $=6$, Doktora $=7$; Hangi Bölgede Yaşıorsunuz? Marmara Bölgesi $=1$; Ege=2, Akdeniz=3, İç Anadolu=4, Karadeniz=5, Doğu Anadolu=6, Güneydoğu Anadolu=7 .

Katılımcılardan beklentiler ile ilgili 21 adet anket sorusu cevaplandırmaları istenmiştir. Beklentilerle ilgili anket sorularının seçenekleri Az Önemli=1, Önemli=2, Çok Önemli=3 olarak üçlü likert ölçeği ile ölçeklenmiştir.

Ankette geçersiz sayılan soru bulunmamaktadır. Araştırmanın ön araştırması ve analizi IBM SPSS 20.0 İstatistik yazılım aracının deneme sürümü kullanılarak yapılmıştır. Verilerin tanımsal analizleri yapılarak frekans tablosu çıkarılmış ve Çok Önemli, Önemli ve Az Önemli olarak değerlendirilen beklentiler belirlenmiş ve pay grafikleri çizilmiştir. 
Örnekleme eleman sayısı 30'dan büyük olduğu için Kolmogrov Smirnov testi ve fissher çarpıklık katsayısının standart hataya oranı ile bulunan çarpıklık değeri +1, 96'nın üzerinde veya -1,96'nın altındaki değerler 0,05 anlamlılık düzeyinde normal kabul edilerek verilerin normal dağılıp dağılmadığı test edilmiştir. Test sonuçları verilerin normal dağılmadığını göstermiştir. Veriler kareleri alınarak normalleştirmeye çalışılmış ancak normal dağılması sağlanamadığı için regresyon analiz testleri uygulanamamıştır.

Ki-kare testleri uygulanarak beklentilerin çok önemli, önemli ya da az önemli olarak değerlendirilmesinin cinsiyet, eğitim durumu ve yaşanılan bölgeden bağımsız olup olmadıkları test edilmiştir.

\section{Bulgular}

Araştırmaya katılan kadınlar, çalışma grubunun \% 62,7'sini, erkekler ise \% 37,3'ünü oluşturmaktadır. Katılımcıların \%61,2'si 6170, \% 20,9'u 71-80, \% 14,9'u 81-90 yaş aralıklarında ve \%3'ü 91 yaşından büyüktür.

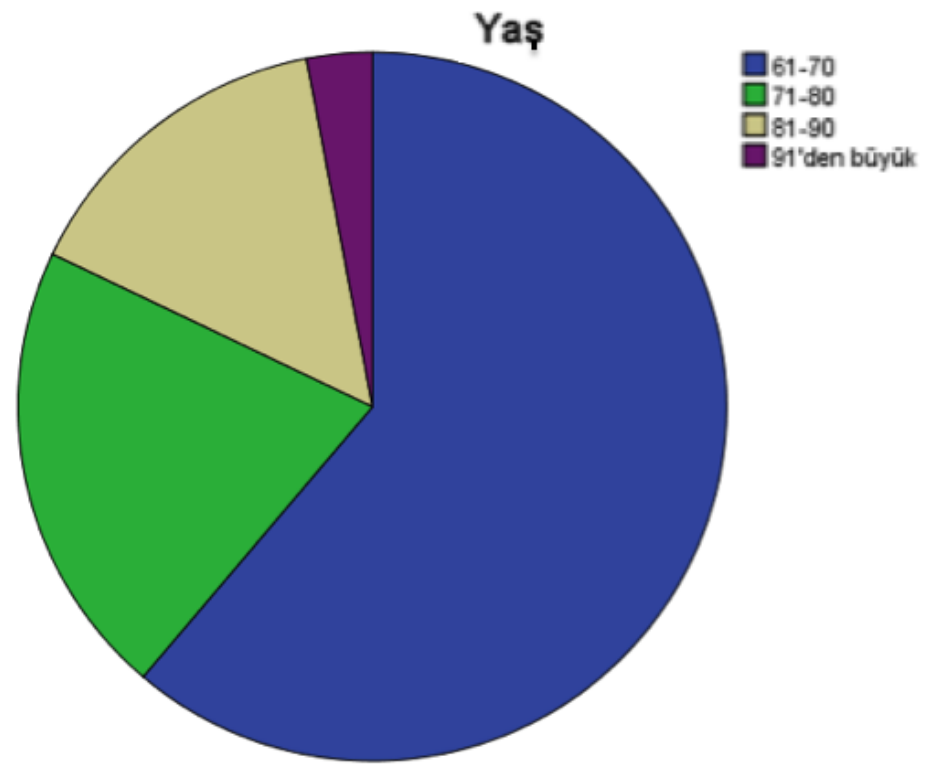

Şekil 3. Katılımcıların yaş aralıkları

Katılımcıların \%6'sı okur yazar değilken, \%21,6'sı ilkokul, \%4,5'u ortaokul, \%36'sı üniversite, \%9,7' si yüksek lisans, \%7,5'u da doktora derecesinde eğitim almışlardır.

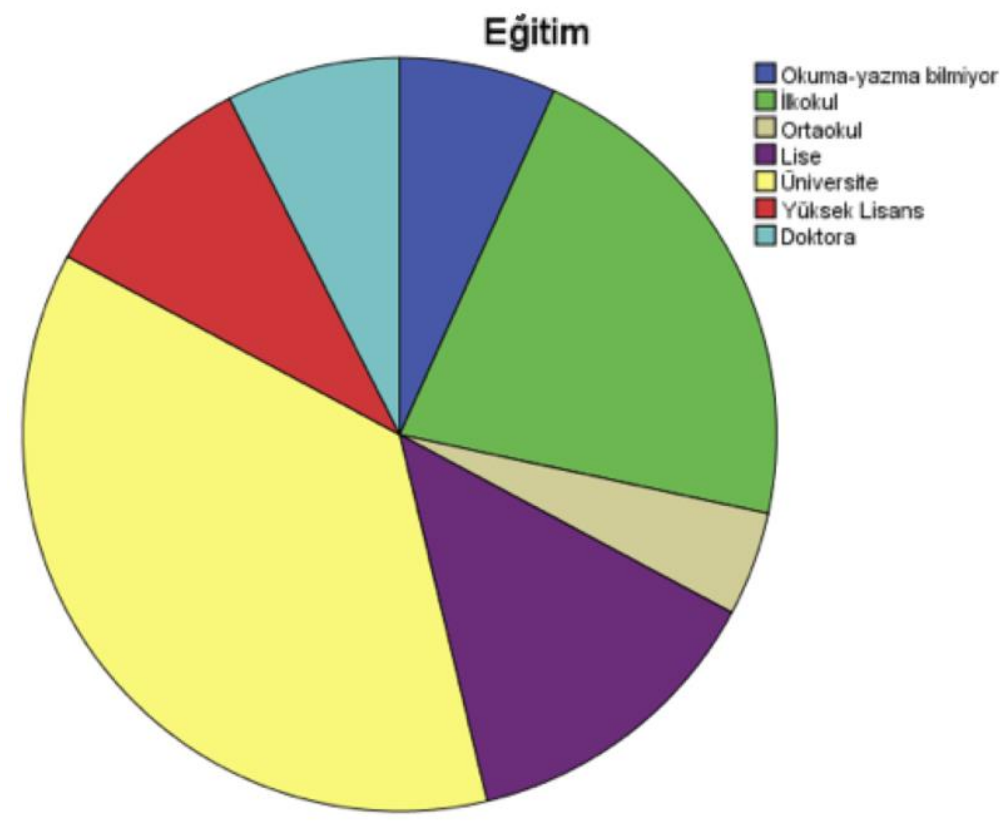

Şekil 4. Katılımcıların ĕgitim durumları

Katılımcıların \%64.2'si Marmara Bölgesi'nde, \%17,9'u Ege Bölgesi'nde, \%5,2'si Akdeniz Bölgesi'nde, \%8,2'si İç Anadolu Bölgesi'nde, \%2,2’si Karadeniz Bölgesi’nde, \%1,5’si Doğu Anadolu Bölgesi’nde, \%0,7'si ise Güneydoğu Anadolu Bölgesi’nde yaşamaktadır. 
Anketin beklentilere yönelik; 3., 4., 5., 6., 7., 8., 9., 16., 18., 19. ve 20. sorular1 "Çok Önemli”; 13., 14., 17., ve 21. soruları “Önemli” ve 1., 2., 9., 10., 11., 12. ve 15. soruları "Az Önemli” olarak değerlendirilmiştir.

Tablo2: Katılimcıların beklentilerine yönelik sorular ve istatistikler

\begin{tabular}{|c|c|c|c|c|c|}
\hline & $\begin{array}{c}\text { Geçerli } \\
\text { Katılımcı } \\
\text { Sayısı N }\end{array}$ & Ortalama & Mod & $\begin{array}{l}\text { Standart } \\
\text { Sapma }\end{array}$ & Varyans \\
\hline Benimle oyun oynasın & 134 & 1,49 & 1 & ,646 & ,417 \\
\hline Enstrüman çalmayı öğretsin & 134 & 1,37 & 1 & 644 & ,414 \\
\hline Evi toplasın temizlesin & 134 & 2,71 & 3 & ,573 & ,328 \\
\hline Benimle sohbet etsin & 134 & 2,28 & 3 & ,750 & ,562 \\
\hline $\begin{array}{l}\text { İstediklerimi getirsin } \\
\text { götürsün }\end{array}$ & 134 & 2,74 & 3 & ,547 & ,300 \\
\hline Egzersiz yaptırsın & 134 & 2,43 & 3 & ,699 & ,488 \\
\hline Hareket etmem için uyarsın & 134 & 2,61 & 3 & 624 & ,390 \\
\hline Beni gözlemlesin & 134 & 2,59 & 3 & ,628 & ,394 \\
\hline TV kumanda etsin & 134 & 2,00 & $1,2,3$ & ,823 & ,677 \\
\hline $\begin{array}{l}\text { Birlikte TV izlesin yorum } \\
\text { yapsın }\end{array}$ & 134 & 1,71 & 1 & ,784 & 614 \\
\hline $\begin{array}{l}\text { Benimle resim yapsın şarkı } \\
\text { söylesin }\end{array}$ & 134 & 1,51 & 1 & ,691 & 477 \\
\hline Yabancı dil öğretsin & 134 & 1,45 & 1 & ,700 & ,490 \\
\hline Çoraplarımı giydirsin & 134 & 2,04 & 2 & ,750 & ,563 \\
\hline Işıkları açıp kapatsın & 134 & 2,28 & 2 & ,678 & ,460 \\
\hline $\begin{array}{l}\text { Bilgisayar oyunu } \\
\text { kart/satranç/tavla oynasın }\end{array}$ & 134 & 1,66 & 1 & 747 & ,558 \\
\hline $\begin{array}{l}\text { Dr'a yakınlarıma haber } \\
\text { versin }\end{array}$ & 134 & 2,84 & 3 & ,440 & 193 \\
\hline Gazete Kitap Okusun & 134 & 2,13 & 2 & ,713 & ,508 \\
\hline $\begin{array}{l}\text { Uyumadan önce camları/dış } \\
\text { kapı kapasın }\end{array}$ & 134 & 2,57 & 3 & ,642 & ,412 \\
\hline $\begin{array}{l}\text { Gece cam / kapı zorlaması } \\
\text { durumunda alarm versin, } \\
\text { yakınlarıma haber versin }\end{array}$ & 134 & 2,83 & 3 & ,434 & 188 \\
\hline $\begin{array}{l}\text { Acil durumda yakınlarıma } \\
\text { durumumu video / fotoğraf } \\
\text { olarak göndersin }\end{array}$ & 134 & 2,78 & 3 & ,481 & 231 \\
\hline $\begin{array}{l}\text { İstediğim radyo kanalını } \\
\text { açsın, müzik dinletsin }\end{array}$ & 134 & 1,84 & 2 & ,717 & ,514 \\
\hline
\end{tabular}

Veriler normal dağılmamaktadır. Ki-kare testi sonuçlarına göre; Sig $>0,05$ olduğundan cinsiyet - beklentiler, yaş - beklentiler, eğitim - beklentiler, bölge - beklentiler değerleri arasında anlamlı farklılık yoktur; değerler birbirinden bağımsızdır.

\section{Tartışma ve Sonuç}

Araştırma sonuçlarına göre, katılımcıların yaşadığı bölge, yaş, cinsiyet ve eğitim durumları ile beklentileri birbirinden bağımsızdır. Katılımcılar yardımcı robottan beklentileri ile ilgili sorulan 21 sorudan yaşlıya egzersiz yaptııılması, yaşlının sağlık durumunun gözlemlenmesi, evin ve yaşlının güvenliğinin sağlanması, yaşlı ile sohbet edilmesi, evin temizlik ve düzeninin sağlanmasına yönelik sorular "Çok Önemli" olarak değerlendirilirken; robotun yaşlıya yabanc1 dil öğretmesi, enstrüman çalmayı öğretmesi, şarkı söylemesi, birlikte televizyon seyretmesi, oyun ve bilgisayar oyunları oynaması gibi yetenekleri “Az Önemli” olarak değerlendirilmiştir.

Robotun televizyonu kumanda etme yeteneğini katılımcıların \%33,6's1 çok önemli, \%32,8'i önemli ve yine \%33,6's1 az önemli olarak değerlendirmiştir. Anketle sorulan 21 beklentinin büyük bölümü yardımcı sosyal robotlar tarafından yerine getirilebilecek destek, refakat ve bakım fonksiyonları dikkate alınarak belirlenmiştir.

Tablo3. Katılımcıların beklentilerine yönelik sorulara verilen cevaplar 


\begin{tabular}{|c|c|c|c|}
\hline & Çok Önemli & Önemli & Az Önemli \\
\hline Benimle oyun oynasın & & & $*$ \\
\hline Enstrüman çalmayı öğretsin & & & $*$ \\
\hline Evi toplasın temizlesin & $*$ & & \\
\hline Benimle sohbet etsin & $*$ & & \\
\hline İstediklerimi getirsin götürsün & $*$ & & \\
\hline Egzersiz yaptırsın & $*$ & & \\
\hline Hareket etmem için uyarsın & $*$ & & \\
\hline Beni gözlemlesin & * & & \\
\hline TV kumanda etsin & $*$ & $*$ & $*$ \\
\hline Birlikte TV izlesin yorum yapsın & & & $*$ \\
\hline Benimle resim yapsın şarkı söylesin & & & $*$ \\
\hline Yabancı dil öğretsin & & & $*$ \\
\hline Çoraplarımı giydirsin & & $*$ & \\
\hline Işıkları açıp kapatsın & & $*$ & \\
\hline Bilgisayar oyunu kart/satranç/tavla oynasın & & & $*$ \\
\hline Dr'a yakınlarıma haber versin & * & & \\
\hline Gazete Kitap Okusun & & $*$ & \\
\hline Uyumadan önce camları/dış kapı kapasın & $*$ & & \\
\hline $\begin{array}{l}\text { Gece cam / kapı zorlaması durumunda alarm versin, } \\
\text { yakınlarıma haber versin }\end{array}$ & $*$ & & \\
\hline $\begin{array}{l}\text { Acil durumda yakınlarıma durumumu video / fotoğraf } \\
\text { olarak göndersin }\end{array}$ & $*$ & & \\
\hline İstediğim radyo kanalını açsın, müzik dinletsin & & $*$ & \\
\hline
\end{tabular}

Günümüzde sağlık hizmeti sağlayıcıları, yaşlı bakım süreçlerinde izlenen yolların belirli bölümlerini yapay zeka (AI) temelli otomasyona terketmeye başladı. Artık biyometrik bilgilerin akıllıca izlenmesinden başlayarak hastalıkların erken teşhisine kadar, bakım süreçlerinin her adımında yapay zeka bulunabilir. Ayrıca yapay zeka, hastalara ve ailelerine tedavi yollarını anlamaları aşamasında yardımcı olmaktadır (Sanyal, 2018). Bununla birlikte, yapay zeka destekli robot teknolojisi ilerledikçe, bakım robotları giderek daha bağımsız hale gelmekte ve fiziksel bakım desteğinin ötesinde daha çok sosyal etkileşimle insanlara yardım sunan refakatçilere dönüşmekte. Metzler ve Barnes'a (2014) göre bakım robotu uygulamaları "arkadaşlık" ve "özen” gibi kavramların anlamını yeniden tanımlayabilir; bakım robotlarıyla etkileşime girmek tek yönlü bir aktivite olamaz, ancak iki yönlü bir aktivitedir ve sonunda insanlar ve robotlar birbirini "biçimlendirir".

Keşifsel bir veri analizi olan bu çalışma ülkemizdeki 60 yaş üzeri nüfusun yardımcı sosyal robot teknolojisinden beklentilerini yansıtması açısından önemlidir. Robotik teknolojileri ülkemizde yaşlılara yönelik bakım ve tıbbi yardım uygulama aşamalarında henüz yaygın olarak kullanılmasa da anket çalışmamız bu teknolojiden beklentilerin, sohbet etme isteği haricinde, sosyal etkileşim ağırlıklı olmadığını göstermiştir. Diğer taraftan, servis tipi robotik teknolojilerinin sunabileceği türden sağlık destek ve güvenlik unsurlarına (esağlık) olan ihtiyaç daha belirgin olarak ifade edilmiştir. Sosyal ve psikolojik desteğe verilen önemin azlığı ülkemizde insansı robot teknolojileri ile etkileşim imkanının olmamasına (çok kısıtlı) bağlanabilir. Önümüzdeki yıllarda e-sağlık sektöründe robotik teknolojilerine yapılacak yatırımlar bakım robotlarının kullanımının ülke genelinde artmasına ve yaşlı bireyler üzerindeki sosyal etkilerinin daha yakından incelenebilmesine olanak verecektir.

\section{Kaynakça}

Administration for Community Living. (11.20.2018). Aging Integrated Database. (02.02.2019) tarihinde http://agid.acl.gov adresinden alındi.

Akdemir, N., Yaşlılarımızın Bakım Sorunları İvedilikle Çözümlenmelidir, Geriatri 2000, 3(4), 169.

Aethon TUG Robot (2015). [Video]. https://www.youtube.com/watch?v=kCDJObCNufg adresinden alınd 1

Aközer, M., Nuhrat, C., \& Say, Ş. (2011). Türkiye'de Yaşlılık Dönemine İlişkin Beklentiler. Aile ve Toplum Eğitim-Kültür ve Araştırma Dergisi, 7(27), 103-127.

Babbage. (5.14.2013). Automation for the elderly Difference Engine: The Caring Robot. The Economist. (03.02.2019) tarihinde https://www.economist.com/babbage/2013/05/14/difference-engine-the-caring-robot adresinden alınd 1

Broadbent, E., Stafford, R., \& MacDonald, B. (2009). Acceptance of healthcare robots for the older population: Review and future directions. International Journal of Social Robotics, (1), 319-330.

Broekens, J., Heerink, M., \& Rosendal, H. (2009). Assistive social robots in elderly care: a review. Gerontechnology, 8, 94-103.

Çakmak, İ. C. Yerinde Yaşlanma Olgusunun Konut Mekan Kullanımı Açısından İrdelenmesi. İstanbul Teknik Üniversitesi, Fen Bilimleri Enstitüsü, Yüksek Lisans Tezi, Ocak 2014.

"Dinsow" Elderly care robot in japan (2016). [Video]. https://www.youtube.com/watch?v=3csjRY8tGoI

Doğan, S. (2017). Yaşlı bakım hizmetleri ve sorunları, SD (Sağlık Düşüncesi ve Tıp Kültürü) Dergisi, (44), 36-39.

Ford, M. (2018). Robotların Yükselişi (3 b.). (C. Duran, Çev.) Kronik.

Gyalog, L. (06.20.2017). Smart home technology for aging in place, June 20 2017, Nokia blog. (05.02.2019) tarihinde https://www.nokia.com/blog/smart-home-technology-aging-place/ adresinden alınd1. 
Kachouie R., Sedighadeli, S., Khosla R., \& Chu, MT. (2014). Socially Assistive Robots in Elderly Care: A Mixed-Method Systematic Literature Review, Intl. Journal of Human-Computer Interaction, (30), 369-393.

Komatsu, T., Kurosawa, R., \& Yamada, S. (2012). How does the difference between users' expectations and perceptions about a robotic agent affect their behavior? International Journal of Social Robotics, (4), 109-116

Lo, A., Guarino, P., Richards, L. G., Haselkorn, J., \& Wittenberg, G. (2010). Robot-Assisted Therapy for Long-Term Upper-Limb Impairment after Stroke. The New England Journal of Medicine, 1772-1783.

Metzler, T. A., Barnes, S. J. (2014). Three dialogues concerning robots in elder care. Nursing Philosophy, 15(1), 4-13.

Mulligan, G. (3.19.2017). Robotlar yaşlıların bakımını üstlenebilir mi? $(11.26,2018)$ tarihinde bbc.com: https://www.bbc.com/turkce/haberler-39303920 adresinden alınd1

Öğüt, S., Öğüt Düzen, K., \& Polat, M. (2017). Huzurevlerinde Yaşayan Yaşlıların Yerinde Yaşlanma Konusundaki Duygu ve Düşünceleri. Manisa Celal Bayar Üniversitesi Sağllk Bilimleri Enstitüsü Dergisi, 522 - 526.

Park, D. (4.20.2016). Robotic Nurse Assistant. (11.25.2018) tarihinde pwp.gatech.edu: http://pwp.gatech.edu/hrl/robotic-nurseassistant/adresinden alınd

ROBEAR: The experimental nursing care robot (2015). [Video]. https://www.youtube.com/watch?v=0LaVwDmLDLw

Sankai, Y. (2007). HAL: Hybrid Assistive Limb based on Cybernics. Advanced Robotics. Springer. doi:DOI: 10.1007/978-3-64214743-2_3

Sanyal, S. (10.31.2018). How is AI revolutionizing elderly care? Forbes. (08.02.2019) tarihinde https://www.forbes.com/sites/shourjyasanyal/2018/10/31/how-is-ai-revolutionizing-elderly-care/\#7a4631a3e07d adresinden alındı

Şentürk, M., \& Kurtkapan, H. (2017). Yaşlılı̆̆ın Mekânsallaşması: Kadıköy Moda’daki Bir Apartman Üzerine Nitel Bir Çalışma. Senex: Yaşlılık Calışmaları Dergisi, (1), 4-19.

Tan, A. (12.31.2015). HumanLike Robot 'Nadine' Who Has a 'Personality, Mood and Emotions' Unveiled in Singapore. (08.02.2019) tarihinde https://abcnews.go.com/Technology/human-robot-nadine-personality-mood-emotions-unveiledsingapore/story?id=36032196 adresinden alınd 1

The soft side of robots: elderly care (2016). [Video]. https://www.youtube.com/watch?v=ppPLDEi82lg

Türkiye İstatistik Kurumu. (2018). İstatistiklerle Yaşlllar, 2017. TÜiK Ankara. Ekim 2018.

UN, 2017.World Population Aging 2017.United Nations Department of Economic and Social Affairs Population Division, New York.

WHO. (2014). WHO Global Forum on Innovations for Aging Populations. Kobe: WHO. 